\title{
Paroxysmal kinesigenic choreoathetosis (PKC): confirmation of linkage to 16p11-q21, but unsuccessful detection of mutations among 157 genes at the PKC-critical region in seven PKC families
}

\author{
Taeko Kikuchi · Masayo Nomura · Hiroaki Tomita · Naoki Harada • \\ Kazuaki Kanai · Tohru Konishi · Ayako Yasuda · Masato Matsuura • \\ Nobumasa Kato $\cdot$ Koh-ichiro Yoshiura $\cdot$ Norio Niikawa \\ Received: 22 November 2006/ Accepted: 13 January 2007/Published online: 14 February 2007 \\ (C) The Japan Society of Human Genetics and Springer 2007
}

\begin{abstract}
Paroxysmal kinesigenic choreoathetosis (PKC) is a paroxysmal movement disorder of unknown cause. Although the PKC-critical region (PKCCR) has been assigned to the pericentromeric region of chromosome 16 by several studies of families from various ethnic backgrounds, the causative gene has not yet been identified. In the present study, we performed linkage and haplotype analysis in four new families with PKC, as well as an intensive polymerase chain reaction (PCR) based mutation analysis in seven families for a total of 1,563 exons from 157 genes mapped around the PKCCR. Consequently, the linkage/haplotype analysis revealed that PKC was assigned to a 24-cM segment between D16S3131 and D16S408, the result confirming the previously defined PKCCR, but being unable to narrow it down. Although the
\end{abstract}

T. Kikuchi $\cdot$ M. Nomura $\cdot$ N. Harada

K. Yoshiura $(\bowtie) \cdot N$. Niikawa

Department of Human Genetics, Nagasaki University

Graduate School of Biomedical Sciences, Sakamoto 1-12-4,

Nagasaki 852-8523, Japan

e-mail: kyoshi@nagasaki-u.ac.jp

T. Kikuchi

Department of Psychiatry, Nagasaki University Graduate

School of Biomedical Sciences, Nagasaki, Japan

H. Tomita

Department of Psychobiology, Graduate School

of Medicine, Tohoku University, Sendai, Japan

N. Harada

Kyushu Medical Science, Nagasaki, Japan

K. Kanai

Department of Neurology, Chiba University School

of Medicine, Chiba, Japan mutation analysis of the 157 genes was unsuccessful at identifying any mutations that were shared by patients from the seven families, two nonsynonymous substitutions, i.e., $6186 \mathrm{C}>\mathrm{A}$ in exon 3 of $S C N N 1 G$ and $45842 \mathrm{~A}>\mathrm{G}$ in exon 29 of $I T G A L$, which were segregated with the disease in Families $\mathrm{C}$ and $\mathrm{F}$, respectively, were not observed in more than 400 normal controls. Thus, one of the two genes, $S C N N 1 G$ and $I T G A L$, could be causative for PKC, but we were not able to find any other mutations that explain the PKC phenotype.

Keywords Paroxysmal kinesigenic choreoathetosis (PKC) · PKC-critical region - Linkage analysis . Mutation analysis $\cdot S C N N 1 G \cdot I T G A L$

T. Konishi

Division of Pediatrics, Nagaoka Ryoikuen, Nagaoka, Japan

A. Yasuda

Department of Pediatrics, Japanese Red Cross Nagoya First

Hospital, Nagoya, Japan

M. Matsuura

Section of Biofunctional Informatics, Graduate School of Allied Health Sciences, Tokyo Medical and Dental

University, Tokyo, Japan

N. Kato

Department of Psychiatry, Faculty of Medicine,

University of Tokyo, Tokyo, Japan

T. Kikuchi · M. Nomura · N. Harada · K. Yoshiura

N. Niikawa

Solution Oriented Research of Science and Technology (SORST), Japan Science and Technology Agency (JST),

Kawaguchi, Japan 


\section{Introduction}

Paroxysmal kinesigenic choreoathetosis (PKC; MIM $128200)$ is a paroxysmal movement disorder characterized by recurrent and brief attacks of unilateral or bilateral involuntary movements, including dystonic posturing, chorea, athetosis, and ballism, which are precipitated by the sudden onset of movements (Kato et al. 2006). The attacks can last as long as a few seconds to a few minutes, occur up to 100 times daily, but usually manifest in childhood or early adolescents, and commonly decrease with age. There is no loss of consciousness during these attacks. The attacks are responsive to anticonvulsants such as carbamazepine or phenytoin. Electroencephalogram (EEG) analysis demonstrates normal or nonspecific abnormalities. Neuroimaging and neuropathological studies resulted in unremarkable findings (Sadamatsu et al. 1999; Nagamitsu et al. 1999). The etiology and pathophysiology of PKC still remain unclear. Some neurologists consider PKC as a form of reflex epilepsy, whereas others believe that basal ganglia dysfunction may play a role in its cause (Kato et al. 2006). Most (40-70\%) were familial cases in which PKC was transmitted in an autosomal dominant mode of inheritance with incomplete penetrance (Tomita et al. 1999; Valente et al. 2000). Males are affected more often than females, with an estimated ratio of 3-4:1 (Bhatia 1999).

We previously performed a genome-wide linkage and haplotype analysis in eight Japanese families with PKC and defined the disease locus within a 12.4-cM region between D16S3093 and D16S416 at 16p11.2q12.1 (Tomita et al. 1999). This PKC-critical region (PKCCR) was confirmed by others (Bennett et al. 2000; Swoboda et al. 2000; Valente et al. 2000; CuencaLeon et al. 2002). In addition, mapped regions for other conditions probably allelic to $\mathrm{PKC}$, such as infantile convulsions and paroxysmal choreoathetosis (ICCA; MIM 602066) and benign familial infantile convulsions (BFIC2; MIM 605751), shared with that for PKC (Lee et al. 1998; Hattori et al. 2000; Swoboda et al. 2000; Caraballo et al. 2001; Weber et al. 2004). Nevertheless, mutations in any genes within the PKCCR have remained uncovered.

Here, we describe the results of the mutation analyses of seven PKC families for a total of 157 genes located at or around the PKCCR, together with linkage/haplotype analysis of four newly identified families.

\section{Materials and methods}

\section{Subjects}

The subjects studied included seven families (Families A-G) with PKC. Two of them (Families F and G) corresponded respectively to Families 1 and 3 in our previous report (Tomita et al. 1999), and five other families (Families A-E, Fig. 1) were those which were newly collected. A total of 21 members, including 16 PKC patients from four of the five families (Families A-D), underwent a linkage and haplotype analysis. In addition, one of each affected individual (we further call them representative patients) chosen from all seven families was subjected to mutation analysis. Blood samples were collected from all participants after obtaining written informed consent, and the study protocol was approved by the Committee for Ethical Issues on Human Genome and Gene Analysis at Nagasaki University.

\section{Genotyping and linkage analysis}

Genomic DNA was isolated from the blood lysate of the 21 participants by phenol-chloroform extraction, followed by ethanol precipitation. To try to narrow down the PKCCR, we performed genotyping and haplotype analysis in the four newly collected PKC families, using 13 microsatellite markers (Table 1) located to a $36-\mathrm{cM}$ region at 16p12-q21 to which PKC has been shown to be linked, as well as using three
Fig. 1 Pedigree of the five families (Families A-E) with paroxysmal kinesigenic choreoathetosis (PKC). The closed squares and circles denote individuals affected with PKC. Although not shown here, Families F and G correspond to Families 1 and 3 reported previously (Tomita et al. 1999)

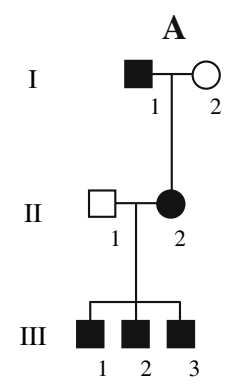

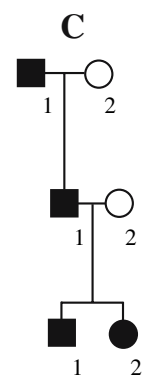

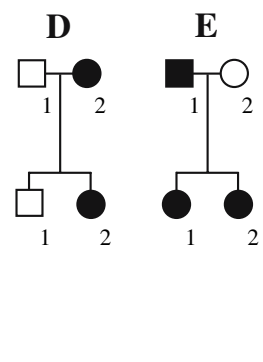


Table 1 Primer sequences of the 12 microsatellite markers used for genotyping and linkage analysis

\begin{tabular}{lll}
\hline Markers & Forward primer $\left(5^{\prime}-3^{\prime}\right)$ & Reverse primer $\left(5^{\prime}-3^{\prime}\right)$ \\
\hline D16S403 & CAAGACTAACGCTGATGGCT & GACAGTGAGGTGGGAATCAAA \\
D16S417 & CTGTCCAACATGCAGCC & TGAAGTCAATCCCACTTGAA \\
D16S3131 & CTGCTTCCATCTTGCC & CTAGCCCCCAAATGTG \\
D16S3093 & CAAGGGCAAAACTCCAT & CCAAAAGGTTGATTCTCTG \\
AC007353-M1 & GCTTAACTACATTTTATCAAGGTTG & TCTGTGGTAGAGAGGCAAAGA \\
AC092368-M1 & GTTTACCAGCCATTTTTAATCAACA & TGAATAAGTGTGTCTTTCAACAAAATT \\
AC092721-M3 & GCCCTGTAATATAATTTGAAGTTG & GGGTTCAAGTGATTCTCCTG \\
D16S3136 & CTCACCTATTGCCCTCAAGAA & CAGAATCTTATGCCATTATT \\
D16S416 & CATAGGACCCTCAGATGTATA & CTGCCTATGGCTAAGAGGACA \\
D16S408 & TGTAACCTTGTGTGCATCCT & CACTCTTATCCCAGGAACCC \\
D16S514 & CAATTCCTTGATGCTACCAT & CTTGTCTAGTGGCTGGAATA \\
D16S3143 & GCTACTGAGGAAACCTTATCC & GGCCATTACAGGAAGTGC \\
\hline
\end{tabular}

Primers of D16S3068 were purchased from the ABI PRISM Linkage Mapping Sets LMS (Applied Biosystems, Foster City, CA)

additional markers (AC007353-M1, AC092368-M1, and AC092721-M3) that were designed by us according to the human genome sequence (http:// genome.cse.ucsc.edu/). Sample DNA was polymerase chain reaction (PCR) amplified for each marker locus with fluorescence-labeled primers. PCR was performed on DNA Thermal Cycler Model 9700 (Applied Biosystems, Foster City, CA) in a 10- $\mu$ l reaction mixture containing $1 \times \mathrm{PCR}$ buffer (Takara Bio, Otsu, Japan), $200 \mu \mathrm{M}$ each of dNTP, $0.5 \mu \mathrm{M}$ each of primer, $10 \mathrm{ng}$ DNA, and 0.25 units ExTaq DNA polymerase HS-version (Takara Bio, Otsu, Japan) under the conditions of denaturation at $94^{\circ} \mathrm{C}$ for $2 \mathrm{~min}, 35$ cycles of $94^{\circ} \mathrm{C}$ for $30 \mathrm{~s}, 58^{\circ} \mathrm{C}$ for $30 \mathrm{~s}$, and $72^{\circ} \mathrm{C}$ for $1 \mathrm{~min}$, and final extension at $72^{\circ} \mathrm{C}$ for 7 min. PCR products were run on an auto-sequencer Model 3100 (Applied Biosystems, Foster City, CA). Allele sizes were analyzed by GeneScan and Genotyper software (Applied Biosystems, Foster City, CA) to determine the genotypes.

\section{Mutation analysis}

We performed PCR-based mutation analysis of the seven representative patients with typical features of PKC. Sequences examined for mutations among the seven patients included those of 1,371 coding exons, excluding the $3^{\prime}$-UTR and $5^{\prime}$-UTR in 117 genes, located at the PKCCR between D16S3093 and D16S416 (Table 1). The analysis in five families (Families A and C-F) was expanded to an additional 192 exons of 40 other genes, whereas because of depletion of genomic DNA, an expanded analysis was not done in the remaining two families. Thus, a total of 1,563 exons in 157 genes were analyzed for mutation (primer sequences are available on request).

\section{Real-time quantitative PCR}

We performed real-time quantitative PCR in six representative patients from Families A and C-G. Six pairs of primers and TaqMan probes were designed for exons 1,6 , and 13 of $S C N N 1 G$, and for exons 1,16 , and 30 of $I T G A L$. PCR was carried out in a $10-\mu l$ reaction mixture containing $5 \mu \mathrm{l}$ of $2 \times$ TaqMan Universal PCR Master mix (Applied Biosystems, Foster City, CA), $0.4 \mu \mathrm{M}$ each of primer, a $0.2-\mu \mathrm{M}$ probe, and $10 \mathrm{ng}$ DNA under the conditions of $2 \mathrm{~min}$ at $50^{\circ} \mathrm{C}, 10 \mathrm{~min}$ at $95^{\circ} \mathrm{C}, 40$ cycles of $15 \mathrm{~s}$ at $95^{\circ} \mathrm{C}$, and $1 \mathrm{~min}$ at $60^{\circ} \mathrm{C}$, with a 7900HT Sequence Detection System (Applied Biosystems, Foster City, CA).

\section{Results}

The haplotype analysis showed that all affected individuals in the four new families share an allele at each locus examined between D16S3131 and D16S408 (Fig. 2). One end of the shared region was defined by a recombination between D16S3131 and D16S3093 in individual III-3 in Family A, and the other end by a recombination between D16S514 and D16S408 in individual III-1 in the same family. These results defined a minimum PKCCR in the four new families within an approximately 24-cM segment between D16S3131 and D16S408. Therefore, the present linkage/haplotype analysis did not contribute to narrow down the previously defined PKCCR.

Among a total of 1,563 exons of 157 genes analyzed, we detected 243 base alterations in the seven representative patients (Fig. 3), 36 of which were base substitutions in coding regions and have not been reported in the dbSNP database (http://www.ncbi.nlm.- 


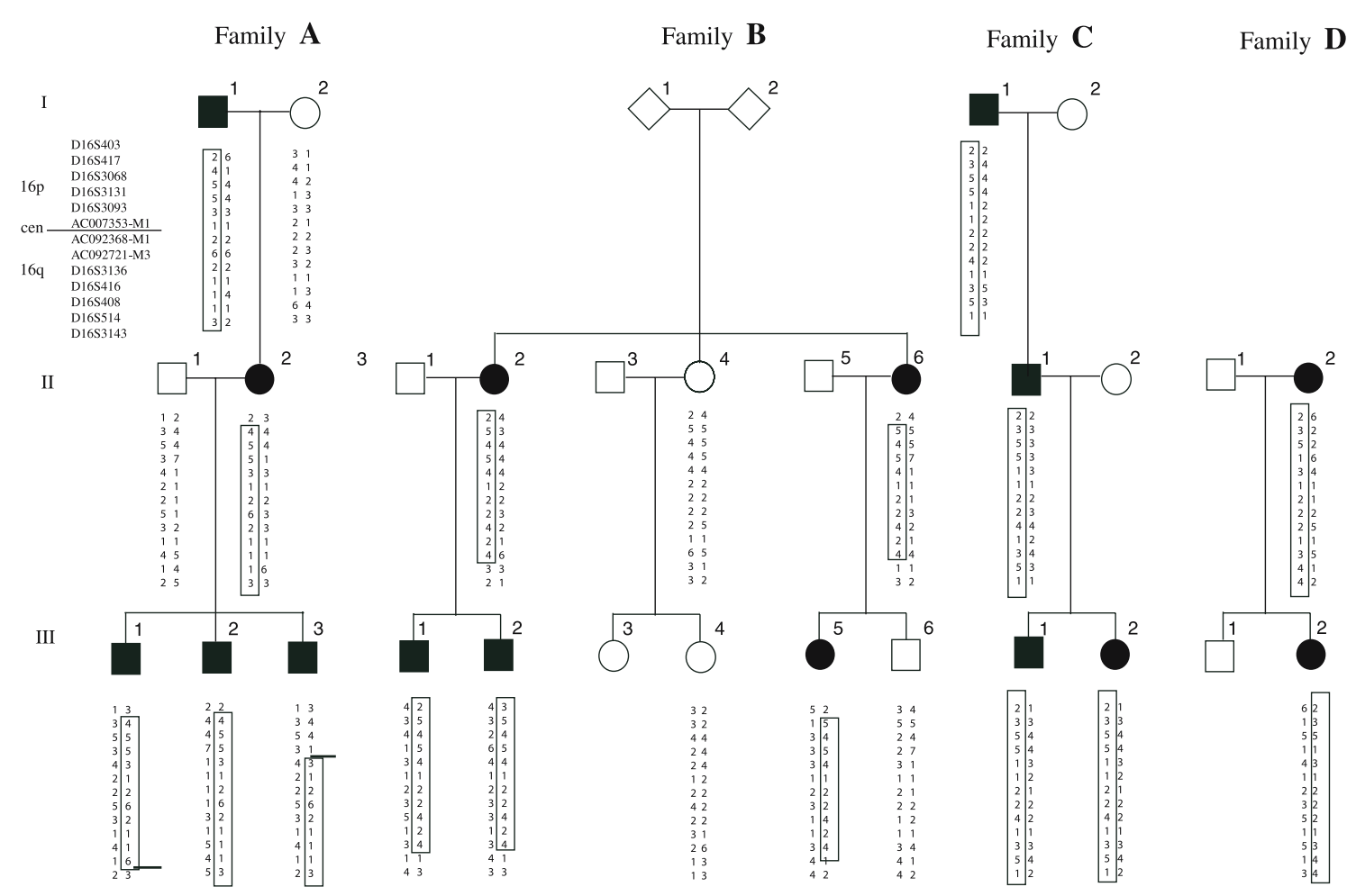

Fig. 2 Haplotype analysis of the four new PKC families (Families A-D). The numbers in boxes represent putative disease haplotypes. The heavy short lines indicate recombination sites

nih.gov/SNP/). Seven of the alterations in six genes were nonsynonymous substitutions resulting in amino-acid substitutions (Table 2). Five of such nonsynonymous substitutions in four genes were observed both in some patients and among 100 normal control individuals. The remaining two, i.e., $6186 \mathrm{C}>\mathrm{A}$ in exon 3 of $S C N N 1 G$ (the gene for sodium channel, nonvoltage-gated 1, gamma) and $45842 \mathrm{~A}>\mathrm{G}$ in exon 29 of ITGAL (the integrin alpha $\mathrm{L}$ precursor gene), observed in Families $\mathrm{C}$ and $\mathrm{F}$, respectively, were not observed among more than 400 normal controls. The real-time quantitative PCR analysis did not detect a duplication or a deletion within the two genes. Of the 35 intronic base changes we identified in the seven patients, none were located at the acceptor or donor splice sites (Fig. 3).

G-banding chromosome analysis at the 400-band level and C-banding analysis revealed that all five patients from Families B-D, F, and G had a normalsized heterochromatin block on chromosome 16 without an inversion (data not shown).
Fig. 3 Classification of 243 base alterations in 157 candidate genes. Information of the newly found single nucleotide polymorphisms (SNPs) is shown in Table 2. None of the novel intronic SNPs are located at any of the acceptor or donor splice sites

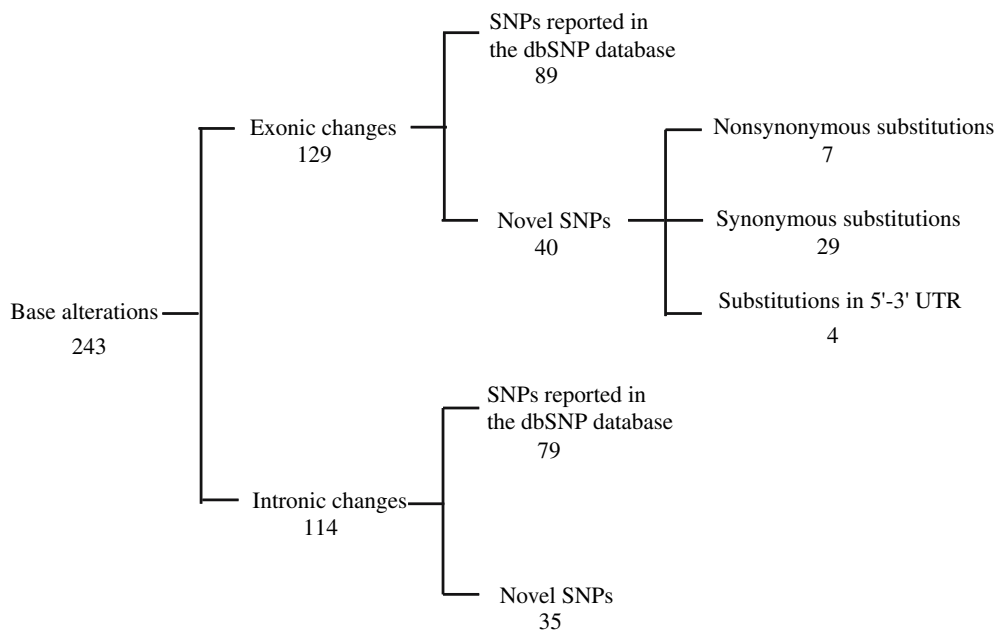


Table 2 List of genes for mutation analysis in the PKC patients, and novel SNPs identified, their positions, nucleotide changes, and amino acid changes

\begin{tabular}{|c|c|c|c|c|c|c|c|c|c|c|c|}
\hline Gene & $\mathrm{E} / \mathrm{I}$ & SNP definition & AA & Gene & $\mathrm{E} / \mathrm{I}$ & SNP definition & AA & Gene & $\mathrm{E} / \mathrm{I}$ & SNP definition & AA \\
\hline HS3ST2* & & & & ASPHD1 & E1 & 515insTGG & & ITGAX* & & & \\
\hline \multirow[t]{2}{*}{ SCNN1G* } & E3 & $6185 \mathrm{G}>\mathrm{T}$ & Y241Y & KCTD13* & I2 & INV2-74A $>$ T & & ITGAD* & $5^{\prime} \mathrm{U}$ & $5^{\prime} \mathrm{U}-13 \mathrm{G}>\mathrm{C}^{\mathrm{a}}$ & \\
\hline & E3 & $6186 \mathrm{C}>\mathrm{A}$ & $\mathrm{P} 242 \mathrm{~T}$ & LOC124446 & & & & & E2 & $943 \mathrm{C}>\mathrm{T}$ & G33G \\
\hline SCNN1B* & & & & TAOK2* & & & & & I7 & INV7+38C $>\mathrm{T}$ & \\
\hline UBPH* & & & & HIRIP3* & & & & & E8 & $14188 \mathrm{~A}>\mathrm{G}$ & $\mathrm{R} 246 \mathrm{R}$ \\
\hline NDUFAB1* & & & & CCDC95 & & & & & E8 & $14253 A>G$ & Y268C \\
\hline \multirow{2}{*}{ PRKCB1* } & E1 & $79 \mathrm{C}>\mathrm{A}$ & $\mathrm{R} 27 \mathrm{R}$ & DOC $2 A^{*}$ & & & & & I9 & INV10-43G $>A$ & \\
\hline & $\mathrm{I} 15$ & INV15+85G $>$ T & & FAM57B & $\mathrm{I} 2$ & INV2+66G $>$ T & & & E16 & $19819 A>G$ & S644G \\
\hline $\mathrm{CACNG}^{*}{ }^{*}$ & & & & ALDOA* & & & & & I17 & INV17+139G $>$ A & \\
\hline \multirow{2}{*}{ TNRC6A* } & E1 & $5^{\prime} \mathrm{U}-12079 \mathrm{~T}>\mathrm{A}$ & & PPP4C* & E1 & $5^{\prime} \mathrm{U}-355-347 \mathrm{del}(\mathrm{CGG}) 3$ & & & I19 & INV19+71C $>$ T & \\
\hline & E21 & $33511 \mathrm{C}>\mathrm{T}$ & $\mathrm{H} 1551 \mathrm{H}$ & TBX6* & & & & & I 27 & INV27+87G $>$ A & \\
\hline \multirow[t]{4}{*}{ SLC5A11* } & I1 & $5^{\prime} \mathrm{U}-12193 \mathrm{~T}>\mathrm{C}$ & & YPEL3* & & & & ARMC5* & & & \\
\hline & $\mathrm{I} 2$ & $\mathrm{INV} 2+6 \mathrm{C}>\mathrm{G}$ & & GDPD3 & & & & TGFB1I1* & E5 & $753 \mathrm{C}>\mathrm{T}$ & P119S \\
\hline & I5 & INV5-30G $>A$ & & MAPK3* & & & & SLC5A2* & & & \\
\hline & I5 & INV5+65T $>C$ & & CORO1A* & & & & C16orf58* & I5 & INV $5+53 \mathrm{G}>\mathrm{A}$ & \\
\hline LCMT1* & & & & SULT1A3* & & & & ERAF* & $3^{\prime} \mathrm{U}$ & $3^{\prime} \mathrm{U}+570 \mathrm{~T}>\mathrm{C}^{\mathrm{a}}$ & \\
\hline \multirow[t]{2}{*}{ IL4R* } & $\mathrm{I} 3$ & $\mathrm{INV} 3+72 \mathrm{~T}>\mathrm{A}$ & & CD2BBP2* & I1 & INV1+493C $>$ T & & MGC3020* & & & \\
\hline & E11 & $22448 \mathrm{~T}>\mathrm{C}$ & L433L & TBC1D10B* & & & & ZNF720* & & & \\
\hline IL21R* & I4 & INV4+51C $>\mathrm{T}$ & & MYLPF & I5 & INV5+27G $>$ A & & ZNF267 & & & \\
\hline GTF3C1* & & & & SEPT1* & & & & TP53TG3* & E3 & 1232insG & \\
\hline \multirow[t]{2}{*}{ KIAA0556* } & I16 & INV16+4T $>C$ & & ZNF553 & E2 & $2434 \mathrm{G}>\mathrm{A}$ & $\mathrm{T} 326 \mathrm{~T}$ & FLJ43855 & & & \\
\hline & E18 & $204044 \mathrm{~A}>\mathrm{G}$ & Q1198Q & ZNF771 & & & & POL3S & & & \\
\hline GSGIL* & & & & ХТР3ТРА* & & & & FLJ46121 & & & \\
\hline \multirow[t]{3}{*}{ XPO6* } & I9 & INV9+31insT & & SEPHS2* & & & & FLJ43980 & E1 & $5^{\prime} \mathrm{U}-15 \mathrm{C}>\mathrm{G}$ & \\
\hline & $\mathrm{I} 15$ & INV15+23G $>C$ & & ITGAL* & $\mathrm{E} 1$ & $5^{\prime} \mathrm{U}-86 \mathrm{C}>\mathrm{T}$ & & SHCBP1* & E5 & $12986 \mathrm{C}>\mathrm{T}$ & $\mathrm{N} 204 \mathrm{~N}$ \\
\hline & E16 & $69120 \mathrm{~T}>\mathrm{C}$ & N740N & & E29 & $45842 \mathrm{~A}>\mathrm{G}$ & K1063R & VPS35* & & & \\
\hline SBK-1 & & & & ZNE768 & & & & ORC6L & E6 & $6328 \mathrm{~A}>\mathrm{G}$ & V193V \\
\hline LOC440350 & & & & ZNF747 & & & & MLCK* & & & \\
\hline LOC440348 & & & & ZNF764 & & & & LOC388272* & & & \\
\hline \multirow[t]{2}{*}{ CLN3* } & $\mathrm{I} 12$ & INV12+36C $>$ T & & ZNF688 & & & & GPT2* & & & \\
\hline & E15 & $14138 \mathrm{~A}>\mathrm{G}$ & $\mathrm{H} 404 \mathrm{R}$ & ZNF785 & & & & DNAJA2* & & & \\
\hline APOB $48 R^{*}$ & & & & ZNF689 & & & & NETO2* & $\mathrm{I} 3$ & INV3-34G $>A$ & \\
\hline IL27* & I5 & INV5-12C $>\mathrm{T}$ & & PRR14 & & & & ITFG1 * & & & \\
\hline NUPR1* & & & & FBS1* & & & & PHKB* & I 28 & INV28+37C $>$ T & \\
\hline CCDC101* & & & & SRCAP* & & & & $\mathrm{ABCC} 12^{*}$ & & & \\
\hline SULTIA2* & & & & PHKG2* & & & & $\mathrm{ABCC} 11^{*}$ & & & \\
\hline SULT1A1* & & & & LOC90835 & & & & LONPL* & & & \\
\hline EIF3S8* & E16 & $20499 \mathrm{C}>\mathrm{T}$ & P725P & RNF40* & & & & SIAH1 & & & \\
\hline ATXN2L* & I13 & INV13+55G $>A$ & & BCL7C* & & & & N4BP1* & & & \\
\hline TUFM* & & & & CTF1* & & & & CBLN1* & & & \\
\hline SH2B* & & & & LOC283932 & & & & FLJ44674 & E1 & $3^{\prime} \mathrm{U}+905 \mathrm{C}>\mathrm{G}$ & \\
\hline ATP2A1* & & & & FBXL19* & & & & C16orf78* & E1 & $45 \mathrm{G}>\mathrm{A}$ & $\mathrm{K} 15 \mathrm{~K}$ \\
\hline RABEP2* & $\mathrm{I} 3$ & INV4-56C $>\mathrm{T}$ & & TMEM142C & & & & & $\mathrm{I} 3$ & $\mathrm{INV} 3+27 \mathrm{~A}>\mathrm{G}$ & \\
\hline CD19* & E4 & $1379 \mathrm{G}>\mathrm{T}$ & P206P & SETD1A* & & & & ZNF423 * & & & \\
\hline \multirow[t]{3}{*}{ SPIN1* } & E7 & $6897 \mathrm{C}>\mathrm{T}$ & S319S & HSD3B7* & & & & C16orf69 & & & \\
\hline & I7 & INV7+278Cdel & & STX1B2* & & & & HEATR3 * & I11 & INV11-44A $>\mathrm{G}$ & \\
\hline & $3^{\prime} \mathrm{U}$ & $3^{\prime} U+9285 C>A^{a}$ & & STX4A* & I8 & INV8 $+55 \mathrm{C}>\mathrm{A}$ & & PAPD5* & & & \\
\hline LAT & E7 & $1259 \mathrm{G}>\mathrm{A}$ & A120A & & I8 & INV8+65C $>\mathrm{T}$ & & $\mathrm{ADCY} 7 *$ & E22 & $24951 \mathrm{~T}>\mathrm{C}$ & Y875Y \\
\hline BOLA2 & & & & ZNF668 & & & & BRD7* & I9 & INV9-26insT & \\
\hline GDYD1* & & & & ZNF646* & I1 & $5^{\prime} \mathrm{U}-108 \mathrm{~T}>\mathrm{G}$ & & & E16 & $48481 \mathrm{G}>\mathrm{A}$ & $\mathrm{T} 570 \mathrm{~T}$ \\
\hline $\mathrm{SPN}^{*}$ & & & & & $\mathrm{E} 2$ & $2722 \mathrm{G}>\mathrm{C}$ & G907A & NKD1* & & & \\
\hline QPRT* & & & & VKORC1* & $3^{\prime} \mathrm{U}$ & $3^{\prime} \mathrm{U}+3730 \mathrm{G}>\mathrm{C}^{\mathrm{a}}$ & & SLIC1* & & & \\
\hline C16orf54 & & & & BCKDK* & & & & CARD15* & & & \\
\hline KIF22* & I12 & INV12+70A $>\mathrm{G}$ & & MYST1* & & & & CYLD* & E17 & $43909 \mathrm{C}>\mathrm{T}$ & D805D \\
\hline MAZ* & & & & PRSS8* & E3 & $2163 \mathrm{C}>\mathrm{T}$ & V46V & SALL1* & & & \\
\hline PRRT2 & & & & PRSS36 & & & & FTS* & & & \\
\hline MVP* & E10 & $11504 \mathrm{C}>\mathrm{T}$ & D525D & FUS* & & & & CAPNS2* & & & \\
\hline C16orf53 & & & & TRIM72 & & & & SLC6A2* & & & \\
\hline CDIPT* & & & & PYCARD* & & & & GNAO1* & & & \\
\hline \multirow[t]{2}{*}{ PSK-1* } & & & & PYDC1* & & & & CNGB1* & E22 & $51134 \mathrm{C}>\mathrm{T}$ & $\mathrm{N} 725 \mathrm{~N}$ \\
\hline & & & & ITGAM* & $\mathrm{I} 2$ & INV2 $+11 \mathrm{~T}>\mathrm{C}$ & & & & & \\
\hline
\end{tabular}

A total of 75 SNPs not reported in the dbSNP database were found in this study

Four SNPs found in 5'-UTR or 3'-UTR happened to be included in the sequenced regions

*Analyzed in seven representative patients: E/I=exon or intron; AA=inferred amino acid change from nonsynonymous SNP; U=UTR 
Fig. 4 The PKC-critical region (PKCCR) summarized by five mapping studies (Tomita et al. 1999; Bennett et al. 2000; Swoboda et al. 2000; Cuenca-Leon et al. 2002, present study), as well as a seemingly second PKC locus (EKD2) by Valente et al. (2000). The location of markers and intermarker distances are from the Généthon map (Dib et al. 1996)

Table 3 List of exons that have not been sequenced in

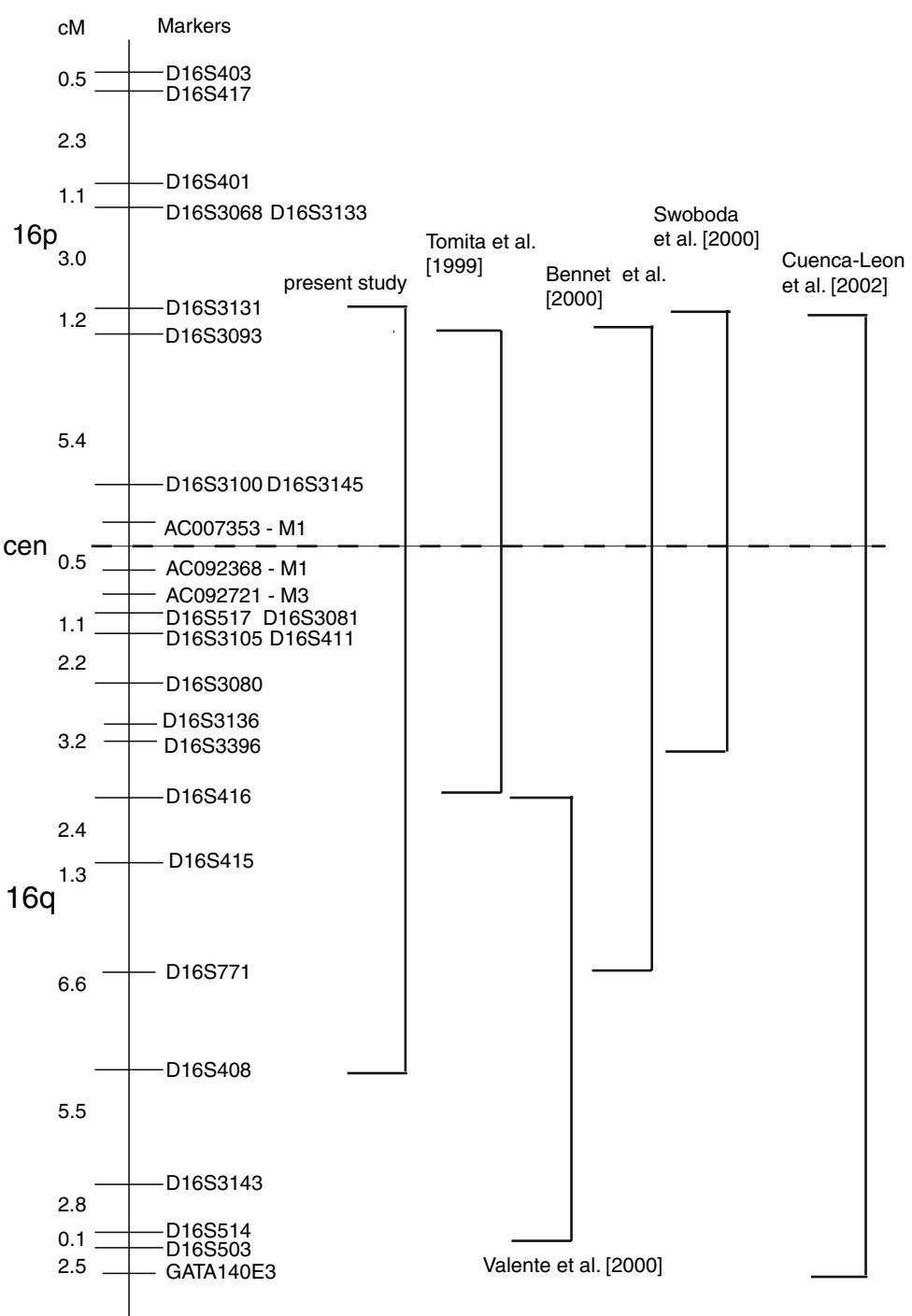
the mutation analysis

\begin{tabular}{ll}
\hline Gene & Exon \\
\hline COX6A2 & Exon 2, Exon 3 \\
$M A Z$ & Exon 1, Exon 2, \\
& Exon 3 \\
VPS35 & Exon 9, Exon 10, \\
& Exon 11 \\
SULT1A1 & Exon 7 \\
SALL1 & Exon 2 \\
$M G C 2474$ & Exon 2 \\
$F L J 43855$ & Exon 5, Exon 7, \\
& Exon 9 \\
\hline
\end{tabular}

\section{Discussion}

The PKCCR was assigned to a segment between D16S3093 and D16S416 in eight Japanese families (Tomita et al. 1999). It was also mapped between D16S3100 and D16S771 in an Afro-Caribbean family (Bennett et al. 2000), between D16S3131 and
D16S3396 in 11 families of diverse ethnicity (Swoboda et al. 2000), between D16S3145 and GATA140E03 in a Spanish family (Cuenca-Leon et al. 2002), and a 24cM segment between D16S3131 and D16S408 in the present study (Fig. 4). Thus, the shortest region of overlap (SRO) did not become narrower than a 12.4cM segment detected by Tomita et al. (1999). Valente et al. (2000) assigned a form of PKC (a second PKC locus, EKD2), in an Indian family, to a segment between D16S416 and D16S503, the region distinct from those mapped by Tomita et al. (1999) and by Swoboda et al. (2000). Furthermore, two other clinical entities, ICCA and BFIC2, were assigned to a region encompassing the centromere of chromosome 16 (Lee et al. 1998; Hattori et al. 2000; Swoboda et al. 2000; Caraballo et al. 2001; Weber et al. 2004). Since all of these loci were confined to a relatively small region, it is likely that all of these paroxysmal movement dis- 
orders actually belong to one disorder and are allelic, as suggested previously (Tomita et al. 1999).

We searched for mutations in almost all proteincoding genes mapped at the PKCCR. In addition, we also analyzed four ion-channel-related genes (CACNG3, SCNN1B, SCNN1G, and CNGB1), albeit located outside the PKCCR, since many episodic neurologic disorders, such as muscle diseases, epilepsy, and movement disorders, are known as ion-channel abnormalities (Bhatia et al. 2000). However, 14 coding exons in seven genes (Table 3) were not analyzed because of difficulties in PCR-amplification.

In the present study on a total of 157 genes, we failed to identify any causative mutations that can explain PKC in all of the seven families examined. However, two nonsynonymous substitutions, 6186C $>\mathrm{A}$ in exon 3 of $S C N N 1 G$ and $45842 \mathrm{~A}>\mathrm{G}$ in exon 29 of $I T G A L$, which were co-segregated with $\mathrm{PKC}$ in Families $\mathrm{C}$ and $\mathrm{F}$, respectively, which were not found in normal control individuals, might be implicated in PKC. In other words, they were not able to be totally ruled out from the candidacy for PKC. It thus remains to be investigated whether another mutation in either gene is found in other PKC families.

Although the mapping of PKC was successful in at least nine studies, causative mutations have been uncovered. This may imply that PKC is caused by aberrations other than exonic mutations, such as a deletion or insertion, in the promoter regions, including the $5^{\prime}$-UTR or $3^{\prime}$-UTR. However, there is still a possibility for usual exonic mutations in a novel gene not annotated in public databases. As PKC itself is, generally, a viable disorder with which patients may show high reproductive fitness, such a mutated allele may be transmitted through many generations. A chromosomal rearrangement is another possibility. The pericentromeric region of chromosome 16 has a large heterochromatin (C-band) block that contains several duplicated regions, through which, frequent chromosomal rearrangements occur (Loftus et al. 1999). It remains also to be seen whether PKC patients within a family share such a variant.

Acknowledgments $\mathrm{We}$ are indebted to the family members for their participation in this research. We especially thank Ms. Y. Noguchi and A. Goto for their technical assistance. N.N. was supported in part by a Grant-in-Aid for Scientific Research (Category S, grant no. 13854024; Priority Areas for Applied Genomics, grant no. 17019055) from the Ministry of Education, Culture, Sports, Science and Technology (MEXT) of Japan, and by Solution Oriented Research of Science and Technology (SORST) from the Japan Science and Technology Agency (JST). K.Y. was supported by a Grant-in-Aid for Scientific Research for Priority Areas (grant no. 17590288) from the MEXT of Japan.

\section{References}

Bennett LB, Roach ES, Bowcock AM (2000) A locus for paroxysmal kinesigenic dyskinesia maps to human chromosome 16. Neurology 54(1):125-130

Bhatia KP (1999) The paroxysmal dyskinesias. J Neurol 246(3):149-155

Bhatia KP, Griggs RC, Ptáček LJ (2000) Episodic movement disorders as channelopathies. Mov Disord 15(3):429-433

Caraballo R, Pavek S, Lemainque A, Gastaldi G, Echenne B, Motte J, Genton P, Cersósimo R, Humbertclaude V, Fejerman N, Monaco AP, Lathrop MG, Rochette J, Szepetowski P (2001) Linkage of benign familial infantile convulsions to chromosome 16p12-q12 suggests allelism to the infantile convulsions and choreoathetosis syndrome. Am J Hum Genet 68(3):788-794

Cuenca-Leon E, Cormand B, Thomson T, Macaya A (2002) Paroxysmal kinesigenic dyskinesia and generalized seizures: clinical and genetic analysis in a Spanish pedigree. Neuropediat 33(6):288-293

Dib C, Faure S, Fizames C, Samson D, Drouot N, Vignal A, Millasseau P, Marc S, Hazan J, Seboun E, Lathrop M, Gyapay G, Morissette J, Weissenbach J (1996) A comprehensive genetic map of the human genome based on 5246 microsatellites. Nature 380:152-154

Hattori H, Fujii T, Nigami H, Higuchi Y, Tsuji M, Hamada Y (2000) Co-segregation of benign infantile convulsions and paroxysmal kinesigenic choreoathetosis. Brain Develop 22(7):432-435

Kato N, Sadamatsu M, Kikuchi T, Niikawa N, Fukuyama Y (2006) Paroxysmal kinesigenic choreoathetosis: from first discovery in 1892 to genetic linkage with benign familial infantile convulsions. Epilepsy Res 70(Suppl 1):174-184

Lee W-L, Tay A, Ong H-T, Goh L-M, Monaco AP, Szepetowski P (1998) Association of infantile convulsions with paroxysmal dyskinesias (ICCA syndrome): confirmation of linkage to human chromosome 16p12-q12 in a Chinese family. Hum Genet 103(5):608-612

Loftus BJ, Kim UJ, Sneddon VP, Kalush F, Brandon R, Fuhrmann J, Mason T, Crosby ML, Barnstead M, Cronin L, Deslattes Mays A, Cao Y, Xu RX, Kang HL, Mitchell S, Eichler EE, Harris PC, Venter JC, Adams MD (1999) Genome duplications and other features in $12 \mathrm{Mb}$ of DNA sequence from human chromosome 16p and 16q. Genomics 60(3):295-308

Nagamitsu S, Matsuishi T, Hashimoto K, Yamashita Y, Aihara M, Shimizu K, Mizuguchi M, Iwamoto H, Saitoh S, Hirano Y, Kato H, Fukuyama Y, Simada M (1999) Multicenter study of paroxysmal dyskinesias in Japan-clinical and pedigree analysis. Mov Disord 14(4):658-663

Sadamatsu M, Masui A, Sakai T, Kunugi H, Nanko S, Kato N (1999) Familial paroxysmal kinesigenic choreoathetosis: an electrophysiologic and genotypic analysis. Epilepsia 40(7):942-949

Swoboda KJ, Soong B, McKenna C, Brunt ER, Litt M, Bale JF Jr, Ashizawa T, Bennett LB, Bowcock AM, Roach ES, Gerson D, Matsuura T, Heydemann PT, Nespeca MP, Jankovic J, Leppert M, Ptáček LJ (2000) Paroxysmal kinesigenic dyskinesia and infantile convulsions: clinical and linkage studies. Neurology 55(2):224-230

Tomita H, Nagamitsu S, Wakui K, Fukushima Y, Yamada K, Sadamitsu M, Masui A, Konishi T, Matsuishi T, Aihara M, Shimizu K, Hashimoto K, Mineta M, Matsushima M, Tsujita T, Saito M, Tanaka H, Tsuji S, Takagi T, Nakamura Y, Nakano S, Kato N, Nakane Y, Niikawa N (1999) Paroxys- 
mal kinesigenic choreoathetosis locus maps to chromosome 16p11.2-q12.1. Am J Hum Genet 65(6):1688-1697

Valente EM, Spacey SD, Wali GM, Bhatia KP, Dixon PH, Wood NW, Davis MB (2000) A second paroxysmal kinesigenic choreoathetosis locus (EKD2) mapping on 16q13-q22.1 indicates a family of genes which give rise to paroxysmal disorders on human chromosome 16. Brain 123(10):2040 2045
Weber YG, Berger A, Bebek N, Maier S, Karafyllakes S, Meyer N, Fukuyama Y, Halbach A, Hikel C, Kurlemann G, Neubauer B, Osawa M, Püst B, Rating D, Saito K, Stephani U, Tauer U, Lehmann-Horn F, Jurkat-Rott K, Lerche H (2004) Benign familial infantile convulsions: linkage to chromosome 16p12-q12 in 14 families. Epilepsia 45(6):601609 